\title{
COMUNICAÇÃO
}

\section{AVALIAÇÃO DO POTENCIAL DE PROPAGAÇÃO POR SEMENTES DE CAPIM-ELEFANTE HEXAPLLÓIDE}

\author{
Evaluation of the potential of propagation by seed of hexaploid elephant-grass
}

\author{
Fausto Souza Sobrinho ${ }^{1}$, Francisco José da Silva Lédo ${ }^{1}$, Antônio Vander Pereira ${ }^{1}, J^{\prime}$ ackson Silva e Oliveira ${ }^{1}$
}

\begin{abstract}
RESUMO
O capim-elefante é uma das gramíneas de maior potencial para produção de leite e carne a pasto. Entretanto, a forma de multiplicação por estacas dificulta a sua maior expansão. O cruzamento interespecífico envolvendo o milheto visa, entre outras coisas, o aumento do tamanho das sementes facilitando a sua propagação. Objetivou-se no presente trabalho, verificar o potencial de germinação de sementes em diferentes progênies de capim-elefante hexaplóide para confirmação da viabilidade de propagação dessa forrageira, por meio de sementes. O experimento foi conduzido na Embrapa Gado de Leite e foram avaliadas 78 progênies de meio-irmãos de capimelefante hexaplóide. Empregou-se o delineamento de blocos casualizados, com três repetições e parcelas de 100 sementes. Em cada parcela foram realizadas três contagens do número de sementes germinadas, em intervalos de sete dias, para obtenção da porcentagem de germinação das sementes. Observaram-se diferenças significativas entre os tratamentos evidenciando a existência de variabilidade no potencial de multiplicação por sementes das progênies de meio-irmãos de capim-elefante hexaplóide. A amplitude de variação para a porcentagem de germinação das sementes foi de 48,67\%. As médias das progênies foram divididas em seis grupos pelo teste de ScottKnott e as progênies 64, 53, 19, 62, 2, 45, 72, 10 e 77 apresentaram melhor desempenho, com germinação das sementes superior a 35\%.
\end{abstract}

Termos para indexação: Pennisetum purpureum, P. glaucum, germinação de sementes, melhoramento de forrageiras.

\begin{abstract}
Elephant grass is a grass with one of the highest potential for milk and beef production under grazing conditions. However, its utilization is limited due to the dissemination method that uses stems for pasture formation. The interespecific cross with pearlmillet, aims to obtain seeds of bigger size to facilitate the propagation of elephant grass. The objective of this paper was to verify the germination potential of different progenies of elephant grass hexaploid seeds to confirm the viability of this dissemination method. The experiment was carried out at Embrapa Gado de Leite, evaluating 78 half-sib progenies of hexaploid elephant grass in a complete randomized block design with three replications and 100 seeds per experimental unit. Three counting of germinated seeds were done in each experimental unit every seven days. Significant differences were observed between progenies showing the existence of variability in the potential for the dissemination when using seeds originated from half-sib progenies of hexaploid elephant grass. The range of variation for seed germination was $48,67 \%$. The progenies were divided into six groups by the Scott-Knott test and the progenies $64,53,19,2,45,72,10$ and 77 presented the best germination rate, with values above $35 \%$.
\end{abstract}

Index terms: Pennisetum purpureum, P. glaucum, seed germination, forage breeding.

(Recebido em 6 de junho de 2006 e aprovado em 24 de novembro de 2006)

O capim-elefante (Pennisetum purpureum Schum.) é, reconhecidamente, uma das gramíneas forrageiras de mais alto potencial produtivo, adaptando-se muito bem às condições de clima e solo de praticamente todo o Brasil. É uma espécie que apresenta ciclo vegetativo perene, crescimento cespitoso, porte elevado, colmos eretos, cilíndricos e cheios, folhas largas e compridas, inflorescência primária terminal do tipo panícula e abundante lançamento de perfilhos aéreos e basais (DIZ, 1994), além de ser preferencialmente alógama, protogínica, mostrando forte depressão endogâmica (JAVIER, 1970; PEREIRA et al., 1997).

Entre as características que favoreceram a disseminação do capim-elefante destacam-se a resistência à seca, boa palatabilidade e alto valor nutritivo quando jovem. Essas qualidades têm contribuído para a seleção da forrageira como a espécie de maior potencial para a produção de leite a pasto (PEREIRA et al., 2001). Contudo, a principal dificuldade existente para a expansão do cultivo do capim-elefante está relacionada à sua forma de propagação, realizada por meio de estacas, o que aumenta o custo de transporte e plantio da forrageira, impossibilita o armazenamento das estacas por longo período (PEREIRA et al., 2003), além de dificultar uma melhor distribuição das cultivares melhoradas; uma vez que, em programas de melhoramento genético desta espécie, é fundamental a utilização de sementes (XAVIER et al., 1993).

1Doutores, Pesquisadores - Embrapa Gado do Leite/CNPGL - Rua Eugênio do Nascimento, 610 - Dom Bosco - $36038-330$ - Juiz de Fora, MG fausto@cnpgl.embrapa.br; ledo@cnpgl.embrapa.br; avanderp@cnpgl.embrapa.br; jackoliv@cnpgl.embrapa.br 
Os híbridos interespecíficos (triplóides e hexaplóides), obtidos pela combinação genética entre o milheto (Pennisetum glaucum) e o capim-elefante, têm-se revelado como uma boa alternativa para a obtenção de cultivares superiores que se propagam por meio de sementes. Além de melhor qualidade forrageira, os híbridos hexaplóides apresentam elevada produção de sementes grandes e viáveis (HANNA, 1999).

Estudos sobre a viabilidade das sementes apontaram elevado potencial da propagação de capimelefante por meio de sementes, obtendo-se até $90 \%$ de germinação (XAVIER et al., 1993). Constatou-se também, que as sementes se mantêm viáveis por até dois anos, quando armazenadas em condições ambientais (MOZZER \& FREIRE, 1980). Apesar de já existir no mercado brasileiro uma cultivar de capim-elefante hexaplóide (cv. Paraíso), propagada por sementes, a maioria dos agricultores e muitos pesquisadores continuam a disseminar a idéia de que o capim-elefante não produz sementes férteis.

Objetivou-se, aqui verificar o potencial de germinação de sementes de 78 progênies de meio-irmãos de capim-elefante hexaplóide para confirmação da viabilidade de propagação desta forrageira por meio de sementes.

O experimento foi conduzido no Laboratório de Genética Vegetal pertencente à Embrapa Gado de Leite, na cidade de Juiz de Fora (MG).

Dentro da população hexaplóide de capim-elefante foram selecionadas fenotipicamente 78 plantas, das quais procedeu-se à colheita individual de sementes no inverno de 2003. Como o capim-elefante é uma espécie alógama admite-se que as sementes de cada planta constituam famílias de meio-irmãos.

Utilizando-se câmaras de germinação programadas com temperaturas de $30^{\circ} \mathrm{C}$ durante o dia, $19^{\circ} \mathrm{C}$ durante a noite e fotoperíodo de 16 horas, foi realizado o teste de germinação das 78 famílias de meio-irmãos de capimelefante, juntamente com uma testemunha constituída por uma amostra de sementes da população original. Empregou-se o delineamento de blocos casualizados com três repetições e parcelas de 100 sementes. Em função da restrição de espaço dentro das câmaras de germinação, as repetições foram realizadas em épocas diferentes. Em cada repetição as sementes foram colocadas em placas de germinação cobertas por papel toalha umedecido e foram realizadas três contagens, em intervalos de sete dias. Ao final da terceira contagem, as sementes eram descartadas e iniciava-se a próxima repetição.
A contagem de sementes germinada foi transformada em porcentagem de germinação de sementes, procedeu-se, a transformação dos dados $(\sqrt{x+1})$ para obtenção de distribuição normal, e foi submetida à análise de variância, seguindo o modelo de blocos casualizados. Empregou-se o teste de Scott \& Knott (1974), para comparação das médias.

A precisão experimental, avaliada por meio da estimativa do coeficiente de variação da análise de variância, foi boa $(\mathrm{CV}=11,4 \%)$, evidenciando confiabilidade nos resultados obtidos. Detectaram-se diferenças significativas entre os tratamentos na análise de variância, indicando que as famílias de meio-irmãos de capim-elefante hexaplóide apresentam variação no potencial de multiplicação por meio de sementes.

As médias da porcentagem de germinação das sementes das 78 famílias de meio-irmãos de capim-elefante hexaplóide, juntamente com a testemunha, estão apresentados na Tabela 1. Observou-se grande discrepância no potencial de germinação das sementes das diferentes famílias de meio-irmãos. A amplitude de variação foi de $48,67 \%$, sendo a família 64 aquela com maior germinação (49\%) e a família 30 com menor germinação, com apenas $0,33 \%$. Resultados semelhantes foram relatados por Mozzer \& Freire (1980) e Xavier et al. (1993), confirmando a existência de variabilidade para a porcentagem de germinação de sementes de capimelefante.

Observa-se contudo, que a magnitude das porcentagens de germinação, encontradas nesse trabalho, foram muito inferiores àquelas relatadas na literatura. Isso provavelmente se deve a dois fatores principais: ponto de colheita e beneficiamento das sementes. Nos trabalhos relatados por Mozzer \& Freire (1980) e Xavier et al. (1993) as inflorescências do capimelefante foram protegidas após a fecundação evitandose a queda das sementes e permitindo a colheita das inflorescências secas e totalmente maduras. Posteriormente, ainda procedeu-se o beneficiamento com a retirada das sementes chochas e mal-formadas. Com isso, somente sementes totalmente desenvolvidas foram avaliadas, obtendo-se porcentagens de germinação próximas de 100\% (pelo menos alguns acessos). Já nesse trabalho, as inflorescências foram colhidas pelo aspecto visual assim que iniciavam mudança de coloração ou queda de sementes, indicando amadurecimento da inflorescência. Entretanto, a antese das flores, bem como o amadurecimento das sementes, não é uniforme. Por isso, foram colhidas muitas sementes 
Tabela 1 - Porcentagem média de germinação de sementes de famílias de meio-irmãos de capim-elefante hexaplóide.

\begin{tabular}{|c|c|c|c|c|c|}
\hline Trat & $\%$ germinação $^{1}$ & Trat & \% germinação & Trat & \% germinação \\
\hline 64 & $49,00^{\mathrm{a}}$ & 31 & $23,33^{c}$ & 6 & $13,00^{\mathrm{d}}$ \\
\hline 53 & $42,67^{\mathrm{a}}$ & 32 & $22,00^{\mathrm{c}}$ & 59 & $12,67^{\mathrm{d}}$ \\
\hline 19 & $42,00^{\mathrm{a}}$ & 75 & $21,33^{\mathrm{c}}$ & 68 & $12,67^{\mathrm{d}}$ \\
\hline 62 & $41,67^{\mathrm{a}}$ & 69 & $20,67^{\mathrm{c}}$ & 66 & $11,33^{\mathrm{d}}$ \\
\hline 2 & $40,67^{\mathrm{a}}$ & 21 & $20,33^{\mathrm{c}}$ & 50 & $11,00^{\mathrm{d}}$ \\
\hline 45 & $39,00^{\mathrm{a}}$ & 48 & $20,33^{\mathrm{c}}$ & 43 & $10,67^{\mathrm{d}}$ \\
\hline 72 & $39,00^{\mathrm{a}}$ & 51 & $20,00^{\mathrm{c}}$ & 46 & $10,67^{\mathrm{d}}$ \\
\hline 10 & $36,00^{\mathrm{a}}$ & 28 & $19,67^{\mathrm{c}}$ & 17 & $10,33^{\mathrm{d}}$ \\
\hline 77 & $35,67^{\mathrm{a}}$ & 38 & $19,33^{\mathrm{c}}$ & 11 & $9,33^{\mathrm{d}}$ \\
\hline 34 & $32,00^{\mathrm{b}}$ & 5 & $19,00^{\mathrm{c}}$ & 35 & $9,00^{\mathrm{d}}$ \\
\hline 14 & $31,33^{\mathrm{b}}$ & 29 & $19,00^{\mathrm{c}}$ & 76 & $9,00^{\mathrm{d}}$ \\
\hline 12 & $31,00^{\mathrm{b}}$ & 39 & $19,00^{\mathrm{c}}$ & 15 & $7,67^{\mathrm{e}}$ \\
\hline 1 & $30,67^{\mathrm{b}}$ & 73 & $18,67^{\mathrm{c}}$ & 37 & $7,33^{\mathrm{e}}$ \\
\hline 9 & $29,67^{b}$ & 49 & $18,00^{\mathrm{c}}$ & 40 & $7,33^{\mathrm{e}}$ \\
\hline 41 & $29,33^{\mathrm{b}}$ & 60 & $17,67^{\mathrm{c}}$ & 18 & $7,00^{\mathrm{e}}$ \\
\hline 65 & $28,67^{\mathrm{b}}$ & 24 & $17,33^{\mathrm{c}}$ & 22 & $7,00^{\mathrm{e}}$ \\
\hline 20 & $28,33^{\mathrm{b}}$ & 44 & $17,33^{\mathrm{c}}$ & 56 & $7,00^{\mathrm{e}}$ \\
\hline 25 & $28,00^{\mathrm{b}}$ & 3 & $16,67^{\mathrm{c}}$ & 16 & $5,67^{\mathrm{e}}$ \\
\hline 27 & $27,67^{\mathrm{b}}$ & 57 & $16,67^{\mathrm{c}}$ & 26 & $5,67^{\mathrm{e}}$ \\
\hline 4 & $27,33^{\mathrm{b}}$ & 36 & $16,00^{\mathrm{d}}$ & 70 & $5,33^{\mathrm{e}}$ \\
\hline 71 & $27,33^{\mathrm{b}}$ & 58 & $15,67^{\mathrm{d}}$ & 67 & $4,33^{\mathrm{e}}$ \\
\hline 8 & $27,00^{\mathrm{b}}$ & 13 & $15,00^{\mathrm{d}}$ & 52 & $4,00^{\mathrm{e}}$ \\
\hline 63 & $27,00^{\mathrm{b}}$ & 61 & $14,67^{\mathrm{d}}$ & 7 & $2,67^{\mathrm{f}}$ \\
\hline 78 & $25,67^{\mathrm{c}}$ & 47 & $14,33^{\mathrm{d}}$ & 42 & $2,00^{\mathrm{f}}$ \\
\hline 23 & $25,00^{\mathrm{c}}$ & 74 & $14,33^{\mathrm{d}}$ & 33 & $0,67^{\mathrm{f}}$ \\
\hline 54 & $23,67^{\mathrm{c}}$ & 55 & $13,33^{\mathrm{d}}$ & 30 & $0,33^{\mathrm{f}}$ \\
\hline
\end{tabular}

Testemunha $10,00^{\mathrm{e}}$

Média 19,34

\begin{abstract}
${ }^{1}$ Médias seguidas por letras diferentes na mesma coluna são estatisticamente distintas pelo teste de Scott \& Knott (1974), com 5\% de probabilidade de erro.

verdes, que não atingiram o completo desenvolvimento. Além do mais, a colheita com base na mudança de coloração das inflorescências é muito subjetiva, dificultando a padronização das sementes e aumentando a porcentagem de sementes verdes. Como o beneficiamento das sementes não foi efetuado, a porcentagem de sementes potencialmente viáveis nas amostras obtidas foi baixo,

contribuindo para as reduzidas magnitudes das porcentagens de germinação obtidas para as famílias de meio-irmãos de capim-elefante hexaplóide, quando comparada com os resultados da literatura. Acredita-se, entretanto, que com o beneficiamento das sementes as médias de germinação serão semelhantes àquelas relatadas na literatura.
\end{abstract}


Esta metodologia de avaliação da germinação de sementes sem o beneficiamento foi utilizada justamente por permitir maior discriminação entre materiais e ser mais prática. Para realização da colheita de sementes, no campo, não é prática a proteção das inflorescências e posterior colheita. Sendo assim, a colheita de sementes em estágios próximos ao amadurecimento da inflorescência reflete melhor uma situação real. Além disso, dentro das famílias pode-se estar selecionando, indiretamente, materiais com retenção de sementes na panícula e com maior homogeneidade de amadurecimento, uma vez que existe maior porcentagem de sementes cheias e potencialmente viáveis.

As médias de germinação de sementes foram agrupadas em seis grupos distintos pelo teste de Scott \& Knott (1974). As famílias 30, 33, 42 e 7 foram as que apresentaram pior desempenho, com porcentagem de germinação inferior a 3\%. Por outro lado, as famílias 64, 53, 19, 62, 2, 45, 72, 10 e 77 constituíram o grupo de melhor desempenho, com germinação das sementes superior a $35 \%$ (Tabela 1). Xavier et al. (1993), avaliando a germinação de 60 clones de capim-elefante, verificaram a formação de sete grupos, concordando com os resultados apresentados e confirmando a grande variabilidade entre os acessos, para a germinação de sementes.

Os resultados obtidos reforçam a possibilidade de multiplicação do capim-elefante por meio de sementes, permitindo a exploração dessa espécie em maiores áreas e também estimulando o seu melhoramento. Como a propagação do capim-elefante por meio de sementes tem sido preconizada por muitos (PEREIRA et al., 2001, 2003; Xavier et al., 1993), a porcentagem de germinação das sementes deve ser mais uma característica a ser considerada, juntamente com aquelas relacionadas à quantidade e qualidade da forragem produzida. Somente seguirão para fases posteriores no melhoramento aqueles materiais que apresentarem bom potencial de produção e germinação de sementes, permitindo, em breve, a obtenção de novas cultivares de capim-elefante hexaplóide com boas características forrageiras, propagadas por sementes.

Conclui-se, portanto, que existe variabilidade para o potencial de germinação de sementes de capim-elefante hexaplóide e as famílias 64, 53, 19, 62, 2, 45, 72, 10 e 77 apresentaram melhor desempenho, com germinação das sementes superior a $35 \%$.

\section{REFERÊNCIAS BIBLIOGRÁFICAS}

DIZ, D. A. Breeding produces and seed production management in pearl millet $x$ elephant grass hexaploids hybrids. 1994. 118 f. Tese (PhD) - University of Florida, Gainsville, 1994.

HANNA, W. W. Melhoramento do capim-elefante. In: PASSOS, L. P.; CARVALHO, L. A.; MARTINS, C. E.; PEREIRA, A. V. (Eds.). Biologia e manejo do capim-elefante. Juiz de Fora: Embrapa Gado de Leite, 1999. p. 17-28.

JAVIER, E. Q. The phenology flowering habit and mode of reproduction of Pennisetum purpureum Shum, Brachiaria mutica (Forsk) Stapt and Panicum maximum Jacq. Ann Arbor, [S.1.], v. 30, n. 9, p. 949-950, 1970. Section B.

MOZZER, O. L.; FREIRE, A. B. Curva de longevidade de sementes de capim-elefante (Pennisetum purpureum, Schum). In: CONGRESSO BRASILEIRO DE ZOOTECNIA, 1.; REUNIÃO ANUAL DA SBZ, 17., 1980, Fortaleza. Anais... Fortaleza: SBZ, 1980. p. 468-469.

PEREIRA, A. V.; MARTINS, C. A.; CARVALHO FILHO, A. B.; CÓSER, A. C.; TELES, F. M.; FERREIRA, R. P.; AMORIM, M. E. T.; ROCHA, A. F. Pioneiro: nova cultivar de capim-elefante para pastejo. In: REUNIÃO DA SBZ, 34., 1997, Juiz de Fora. Anais... Juiz de Fora: SBZ, 1997. p. $102-104$

PEREIRA, A. V.; SOUZA SOBRINHO, F.; SOUZA, F. H. D.; LÉDO, F. J. S. Tendências do melhoramento genético e produção de sementes forrageira no Brasil. In: SIMPÓSIO SOBRE ATUALIZAÇÃO EM GENÉTICA E MELHORAMENTO DE PLANTAS, 4., 2003, Lavras. Anais... Lavras: UFLA, 2003. p. 36-63.

PEREIRA, A. V.; VALLE, C. B.; FERREIRA, R. P.; MILES, J. W. Melhoramento de forrageiras tropicais. In: NASS, L. L.; VALOIS, C. C.; MELO, I. S.; VALADARES-INGRES, M. C. (Eds.). Recursos genéticos e melhoramento de plantas. Rondonópolis: Fundação Mato Grosso, 2001. p. 549-602.

SCOTT, A. J.; KNOTT, M. A. A cluster analysis method for grouping means in the analysis of variance. Biometrics, Raleigh, v. 30, n. 3, p. 507-512, Sept. 1974.

XAVIER, D. F.; DAHER, D. F.; BOTREL, M. A.; PEREIRA, J. R. Poder germinativo de sementes de capim-elefante. Revista Brasileira de Zootecnia, Viçosa, v. 22, n. 4, p. 565571, 1993. 